Article

\title{
Phytochemicals of Euphorbia lathyris L. and Their Antioxidant Activities
}

\author{
Lizhen Zhang ${ }^{1, *}$, Chu Wang ${ }^{1}$, Qiuxia Meng ${ }^{2}$, Qin Tian ${ }^{1}$, Yu Niu ${ }^{3}$ and Wei Niu ${ }^{4}$ \\ 1 School of Life Science, Shanxi University, Taiyuan 030006, China; 15835107995@163.com (C.W.); \\ 18834823413@163.com (Q.T.) \\ 2 Institute of Agricultural Environment and Resources, Shanxi Academy of Agricultural Sciences, \\ Taiyuan 030006, China; qiuxia_meng@126.com \\ 3 Institute of Agricultural Resources and Economic Research, Shanxi Academy of Agricultural Sciences, \\ Taiyuan 030006, China; kayneo@126.com \\ 4 Shanxi Academy of Agricultural Sciences, Taiyuan 03006, China; niuwillame@163.com \\ * Correspondence: lizhen@sxu.edu.cn; Tel.: +86-351-7010599
}

Received: 23 June 2017; Accepted: 3 August 2017; Published: 18 August 2017

\begin{abstract}
The objectives of this study were to characterize the antioxidant capacities and phytochemicals such as phenolics and flavonoids in four parts of Euphorbia lathyris L. HPLC was employed to detect the type and content of phenolic acids and flavonoids in the root, stem, seed, and testa of the plant. The total phenolic content (TPC) and total flavonoid content (TFC) were different among various parts of E. lathyris. The highest TPC were found in the testa (290.46 $\pm 15.09 \mathrm{mg}$ of gallic acid equiv /100 g dry weight (DW)). However, the root contained the highest TFC (215.68 $\pm 3.10 \mathrm{mg}$ of rutin equiv/g DW). Of the different antioxidant activities detected, DPPH free radical scavenging activity was highest in the testa $(61.29 \pm 0.29 \mathrm{mmol}$ Trolox/100 g DW), but the highest FRAP antioxidant activity was found in the seed (1131.25 $\pm 58.68 \mathrm{mg} \mathrm{FeSO} 4 / 100 \mathrm{~g}$ DW of free compounds and $1927.43 \pm 52.13 \mathrm{mg} \mathrm{FeSO}_{4} / 100 \mathrm{~g}$ DW of bound compounds). There was a positive correlation between the total phenolic contents and DPPH free radical scavenging activity in different parts of E. lathyris.
\end{abstract}

Keywords: Caper spurge; phenolic compounds; flavonoids; HPLC; antioxidative activities

\section{Introduction}

Caper spurge (Euphorbia lathyris L.), a well-known herb plant of the family Euphorbiaceae, has been widely cultivated as a bioenergy crop or for traditional Asian medicine. E. lathyris is widely distributed in all climate types, including Europe, North and South America, Central Asia, East Asia, and North Africa. In Western Europe and the USA, it is used as a source of bio-fuel and biomass because of its high contents of hydrocarbons and fatty acids [1,2]. In traditional Chinese medicine, its seeds are prescribed to treat hydropsy, ascites, coprostasis, amenorrhea, scabies, and snakebite [3], and it has toxicological effects similar to those of croton oil. Previous biological studies have indicated that it displays antitumor effects in curing leucocythemia, esophagus cancer, and skin cancer [4].

To our knowledge, the phytochemical components of the root, seed, and aerial parts of E. lathyris have attracted increasing attention in the past few decades, mostly for human health applications. Phytochemicals of E. lathyris have shown the presence of varied metabolites, such as diterpene [5-7], euphorbetin, aesculetin, daphnetin, $\beta$-sitosterol, kaempferol-3-glucuronide [8], vitexicarpin, artemetin, daucosterol, p-hyfroxybenzoic acid [9], flavones, and flavonol glucosides [10]. The diversity of chemical compounds in this herb has been considered to be of biological interest. Phytochemicals may exist in free and bound forms. Bound form materials are conjugated to the cell wall. To our knowledge, 
most previous studies have reported different profiles of grains. There is only limited literature on the complete profile (free and bound) of the chemical compounds of herbs.

Medicinal plant parts have multiple biological effects including antioxidant activity. In spite of its hydrocarbon-like compounds and medicinal benefits, no data have been previously reported on the antioxidative activity of E. lathyris. Previous studies found that the seeds contained fats, proteins, coumarins, and a series of diterpenoids, but the study of phenolic compounds and flavonoids in different parts of E. lathyris is still very rare. Therefore, the objectives of the present study were (1) to determine the phytochemical profiles of the total phenolic and flavonoid contents, including both free and bound forms; and (2) to determine the antioxidant activity in different parts of E. lathyris.

\section{Results and Discussion}

\subsection{Total Phenolic Content (TPC) of Different Parts of E. lathyris}

This study is the first to report the total phenolic content in E. lathyris. The free, bound, and total phenolic contents are presented in Table 1 . The free phenolic content in testa was highest $(p<0.05)$ $(222.12 \pm 12.09 \mathrm{mg}$ gallic acid equiv (GAE)/100 g dry weight (DW)), followed by those in stem $(161.17 \pm 8.64 \mathrm{mg}$ GAE/100 $\mathrm{g}$ DW) and seed $(95.04 \pm 8.90 \mathrm{mg}$ GAE/100 $\mathrm{g} \mathrm{DW})$. The highest bound phenolic content was also found $(p<0.05)$ in testa $(68.34 \pm 3.00 \mathrm{mg} \mathrm{GAE} / 100 \mathrm{~g} \mathrm{DW})$, followed by stem $(53.97 \pm 6.36 \mathrm{mg} \mathrm{GAE} / 100 \mathrm{~g} \mathrm{DW})$ and root (52.55 $\pm 0.44 \mathrm{mg}$ GAE/100 g DW). Similarly, the total phenolic content $(p<0.05)$ in testa was highest $(290.46 \pm 15.09 \mathrm{mg}$ GAE $/ 100 \mathrm{~g} \mathrm{DW})$, followed by those in stem $(215.14 \pm 15.00 \mathrm{mg} \mathrm{GAE} / 100 \mathrm{~g} \mathrm{DW})$ and root $(143.00 \pm 5.04 \mathrm{mg} \mathrm{GAE} / 100 \mathrm{~g} \mathrm{DW})$. There were significant differences in the total phenolic contents among the four parts $(p<0.05)$. The free phenolic content of testa was significantly higher than those in stem, root, and seed $(p<0.05)$. In addition, the free phenolic content of stem was significantly higher than those in root and seed, but no significant differences in the free phenolic content were found between root and seed $(p>0.05)$. The bound phenolic content of testa was significantly higher than those of stem, root, and seed $(p<0.05)$. In addition, no significant differences in the bound phenolic content were seen between stem and root $(p>0.05)$, but their bound phenolic contents were significantly higher than that of seed $(p<0.05)$. Surveswaran et al. [10] reported that the total phenolic levels of E. lathyris was 1.15g GAE/100 g of dry sample using aqueous solutions of methanol. This method at best extracted only the free or loosely attached and more readily soluble phenolic compounds in the samples, and did not extract phenolic compounds tightly bound to cell wall materials [11]. Moreover, no alkali hydrolysis or further extraction was performed. However, the value reported in their study was significantly higher than those reported in the present study, which were perhaps influenced by the genotype of E. lathyris.

Table 1. Contents of phenolic acids of Euphorbia lathyris (mg galic acid equiv/100 g dry weight (DW)).

\begin{tabular}{cccc}
\hline Part & Free Phenolics & Bound Phenolics & Total Phenolics \\
\hline stem & $161.17 \pm 8.64^{\mathrm{b}}$ & $53.97 \pm 6.36^{\mathrm{b}}$ & $215.14 \pm 15.00^{\mathrm{b}}$ \\
root & $90.45 \pm 4.60^{\mathrm{c}}$ & $52.55 \pm 0.44^{\mathrm{b}}$ & $143.00 \pm 5.04^{\mathrm{c}}$ \\
seed & $95.04 \pm 8.90^{\mathrm{c}}$ & $22.40 \pm 0.53^{\mathrm{c}}$ & $117.44 \pm 9.43^{\mathrm{d}}$ \\
testa & $222.12 \pm 12.09^{\mathrm{a}}$ & $68.34 \pm 3.00^{\mathrm{a}}$ & $290.46 \pm 15.09^{\mathrm{a}}$ \\
\hline
\end{tabular}

Values with different letters in common columns are significantly different $(p<0.05, n=3)$.

In plants, phenolics that provide many health benefits concentrate in the corn or vegetable. We compared the TPC of different parts of E. lathyris in this study. It was found that the TPC of the testa was significantly higher than those in the stem, root, and seed. The same results were obtained in many other economically important fruits, including apple, grape berry, and olive, whose peels (or skins) contained higher TPC than other tissues [12]. The TPC ranged from 290.46 to $117.44 \mathrm{mg}$ GAE/100 $\mathrm{g}$ DW among different parts of E. lathyris. Our results were in accordance with the data reported by Liu [13], who found that among all of the plant extracts investigated, the total phenolics ranged 
from 0.57 to $280.46 \mathrm{mg} \mathrm{GAE} / \mathrm{g}$. Cai et al. [14] found that phenolic compounds were the dominant antioxidant components in the traditional Chinese medicinal herbs associated with anticancer activity. In the present study, high TPC was obtained from E. lathyris, indicating that E. lathyris is a good source of antioxidants with health benefits.

\subsection{Total Flavonoid Content (TFC) of Different Parts of E. lathyris}

This study was the first to report the total flavonoid content in E. lathyris. The free, bound, and total flavonoid contents are presented in Table 2 . The free flavonoid content in root was highest $(p<0.05$ (144.67 $\pm 2.89 \mathrm{mg}$ rutin equiv (RE)/100 g DW), followed by those in testa $(42.36 \pm 0.80 \mathrm{mg}$ $\mathrm{RE} / 100 \mathrm{~g} \mathrm{DW})$ and seed $(4.23 \pm 0.17 \mathrm{mg}$ RE/100 $\mathrm{g} \mathrm{DW})$. The highest bound flavonoid content was also recorded $(p<0.05)$ in root $(71.01 \pm 0.21 \mathrm{mg} R E / 100 \mathrm{~g} \mathrm{DW})$, followed by those in stem $(42.28 \pm 2.34 \mathrm{mg}$ $\mathrm{RE} / 100 \mathrm{~g} \mathrm{DW})$ and seed $(7.49 \pm 0.22 \mathrm{mg}$ RE/100 g DW). Similarly, the total flavonoid content $(p<0.05)$ in root was highest $(215.68 \pm 3.1 \mathrm{mg} R E / 100 \mathrm{~g} \mathrm{DW})$, followed by those in stem $(45.43 \pm 2.63 \mathrm{mg}$ $\mathrm{RE} / 100 \mathrm{~g} \mathrm{DW})$ and testa $(43.56 \pm 0.93 \mathrm{mg} \mathrm{RE} / 100 \mathrm{~g} \mathrm{DW})$. There were significant differences in the bound flavonoid content between the four plant parts $(p<0.05)$. The free flavonoid content of root was significantly higher than those of stem, seed, and testa $(p<0.05)$. The total flavonoid content of root was significantly higher than those of stem, seed, and testa $(p<0.05)$.

Table 2. Contents of flavonoids of Euphorbia lathyris (mg of rutin equiv/100 g DW).

\begin{tabular}{cccc}
\hline Part & Free Flavonoids & Bound Flavonoids & Total Flavonoids \\
\hline stem & $3.15 \pm 0.29^{\mathrm{c}}$ & $42.28 \pm 2.34^{\mathrm{b}}$ & $45.43 \pm 2.63^{\mathrm{b}}$ \\
root & $144.67 \pm 2.89^{\mathrm{a}}$ & $71.01 \pm 0.21^{\mathrm{a}}$ & $215.68 \pm 3.1^{\mathrm{a}}$ \\
seed & $4.23 \pm 0.17^{\mathrm{c}}$ & $7.49 \pm 0.22^{\mathrm{c}}$ & $11.72 \pm 0.39^{\mathrm{c}}$ \\
testa & $42.36 \pm 0.80^{\mathrm{b}}$ & $1.20 \pm 0.13^{\mathrm{d}}$ & $43.56 \pm 0.93^{\mathrm{b}}$ \\
\hline
\end{tabular}

Values with different letters in common columns are significantly different $(p<0.05, n=3)$.

Flavonoids are regarded as important antioxidants in herbal medicine [15]. We found that the TFC in root of E. lathyris was almost 20-fold higher than that in its seed. The TFC ranged from $11.72 \mathrm{mg}$ $\mathrm{RE} / 100 \mathrm{~g}$ DW to $215.68 \mathrm{mg} \mathrm{RE} / 100 \mathrm{~g}$ DW among different parts of the plant. It is difficult to directly compare our results with others, because the research on flavonoids in different parts of E. lathyris remains scarce. However, when compared with the reported flavonoid contents of other plants, such as Gordon Euryale seed (1.39 mg RE/g DW), Chinese dwarf cherry seed (2.17 mg RE/g DW), platycodon root (0.95 mg RE/g DW), bitter apricot seed (0.90 mg RE/g DW), or ginkgo seed (0.62 mg RE/g DW) [13], the TFC of E. lathyris was considerably higher. The presence of a high flavonoid content is considered beneficial for health, as flavanoids are known to be antioxidative and anti-inflammatory, and exhibit many other health benefits as well [16,17]. E. lathyris is also a promising potential source of flavonoid compounds. However, the identification of the flavonoid compounds of E. lathyris remains under-investigated, and thus is worthy of further research.

\subsection{HPLC Analysis of Phenolic Compounds}

An HPLC chromatogram of mixed phenolic acid standards at $280 \mathrm{~nm}$ is shown in Figure 1, and HPLC chromatograms of one sample are provided in Figure 2. The contents of individual phenolic compounds in different parts of E. lathyris are listed in Table 3.

It was noticed that the free phenolics of the stem included gallic acid, chlorogenic acid, and ferulic acid, while the bound phenolics of stem included gallic acid and chlorogenic acid. Four types of phenolic acids presented in free form in root, namely, gallic acid, chlorogenic acid, vanillic acid, and ferulic acid, while two types of phenolic acids presented in bound form in root, specifically gallic acid and chlorogenic acid. In the seed, gallic acid, vanillic acid, and ferulic acid were found as the three free forms of phenolic acid, while gallic acid and chlorogenic acid presented as two bound form of phenolic acid. 


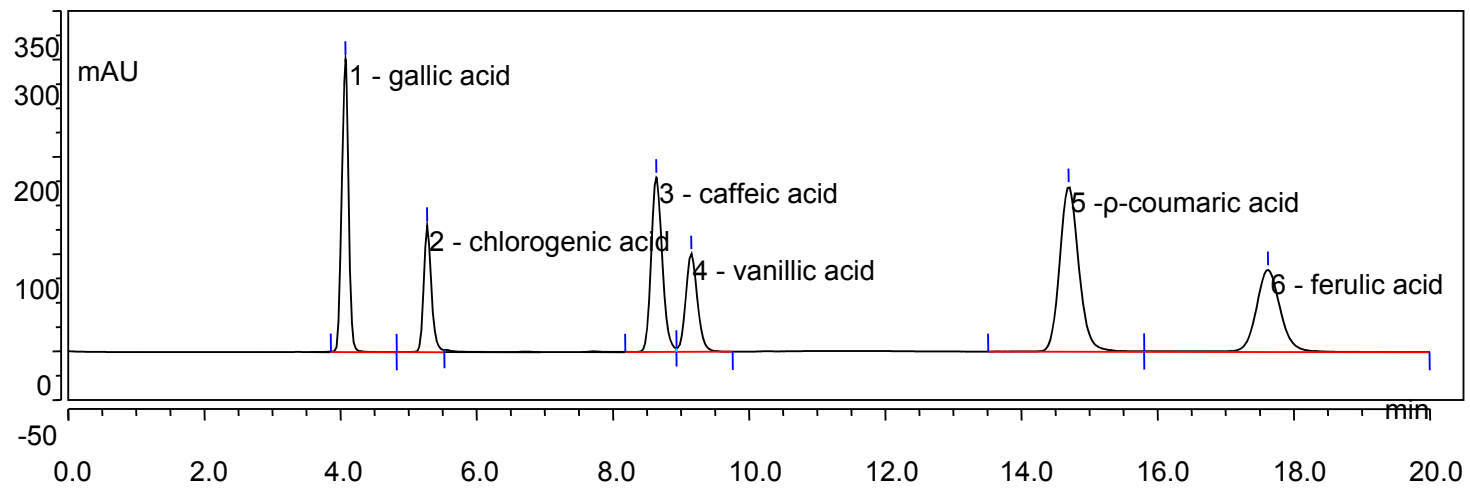

Figure 1. HPLC chromatogram of mixed phenolic acid standards at $280 \mathrm{~nm}$. Gallic acid-4.072 min; chlorogenic acid-5.270 min; caffeic acid-8.635 min; vanillic acid-9.148 min; $p$-coumaric acid-14.692 $\mathrm{min}$; ferulic acid-17.617 $\mathrm{min}$.

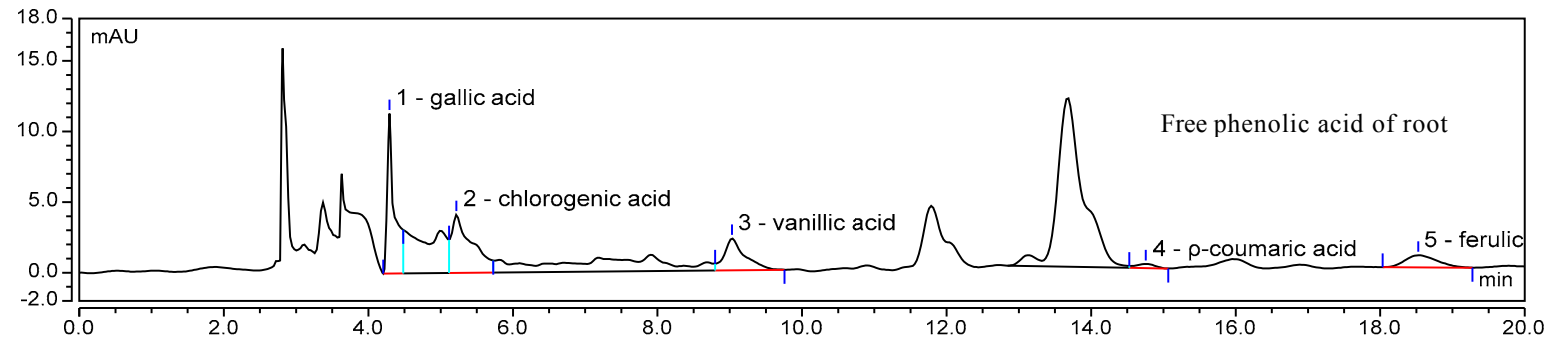

Figure 2. HPLC chromatogram of one sample of phenolic acid.

Table 3. Composition and contents of phenolic acid in Euphorbia lathyris L. samples (mg/100 g DW).

\begin{tabular}{|c|c|c|c|c|}
\hline Part & Composition & Free & Bound & Total \\
\hline stem & $\begin{array}{c}\text { gallic acid } \\
\text { chlorogenic acid } \\
\text { vanillic acid } \\
\text { ferulic acid }\end{array}$ & $\begin{array}{c}1.16 \pm 0.01 \\
0.38 \pm 0.01 \\
\text { nd } \\
0.52 \pm 0.10\end{array}$ & $\begin{array}{c}0.83 \pm 0.04 \\
3.53 \pm 0.06 \\
\text { nd } \\
\text { nd }\end{array}$ & $\begin{array}{c}1.99 \pm 0.20 \\
3.91 \pm 0.07 \\
\text { nd } \\
0.52 \pm 0.10\end{array}$ \\
\hline root & $\begin{array}{c}\text { gallic acid } \\
\text { chlorogenic acid } \\
\text { vanillic acid } \\
p \text {-coumaric acid } \\
\text { ferulic acid }\end{array}$ & $\begin{array}{c}1.19 \pm 0.15 \\
1.03 \pm 0.04 \\
0.50 \pm 0.06 \\
\text { nd } \\
0.97 \pm 0.07\end{array}$ & $\begin{array}{c}1.04 \pm 0.14 \\
7.83 \pm 0.15 \\
\text { nd } \\
\text { nd } \\
\text { nd }\end{array}$ & $\begin{array}{c}2.23 \pm 0.29 \\
8.86 \pm 0.19 \\
0.50 \pm 0.06 \\
\text { nd } \\
0.97 \pm 0.07\end{array}$ \\
\hline seed & $\begin{array}{c}\text { gallic acid } \\
\text { chlorogenic acid } \\
\text { vanillic acid } \\
p \text {-coumaric acid } \\
\text { ferulic acid }\end{array}$ & $\begin{array}{c}1.57 \pm 0.06 \\
\text { nd } \\
0.08 \pm 0.01 \\
\text { nd } \\
0.59 \pm 0.06\end{array}$ & $\begin{array}{c}0.95 \pm 0.07 \\
0.82 \pm 0.03 \\
\text { nd } \\
\text { nd } \\
\text { nd }\end{array}$ & $\begin{array}{c}2.52 \pm 0.13 \\
0.82 \pm 0.03 \\
0.08 \pm 0.01 \\
\text { nd } \\
0.59 \pm 0.06\end{array}$ \\
\hline testa & $\begin{array}{c}\text { gallic acid } \\
\text { chlorogenic acid } \\
\text { caffeic acid } \\
p \text {-coumaric acid } \\
\text { ferulic acid }\end{array}$ & $\begin{array}{l}1.79 \pm 0.01 \\
2.97 \pm 0.18 \\
5.36 \pm 0.21 \\
4.88 \pm 0.09 \\
1.18 \pm 0.11\end{array}$ & $\begin{array}{l}\text { nd } \\
\text { nd } \\
\text { nd } \\
\text { nd } \\
\text { nd }\end{array}$ & $\begin{array}{l}1.79 \pm 0.01 \\
2.97 \pm 0.18 \\
5.36 \pm 0.21 \\
4.88 \pm 0.09 \\
1.18 \pm 0.11\end{array}$ \\
\hline
\end{tabular}

Caffeic acid and $p$-coumaric acid were only found in the testa. Ferulic acid was significantly higher in testa than in the root, seed, and stem. Chlorogenic acid was significantly higher in root than in the stem, testa, and seed. Jiao et al. [9] detected palmitic acid, benzoic acid, $p$-hydroxybenzoic acid, and oleic acid in the seed of E. lathyris on the basis of spectroscopic investigations. 


\subsection{HPLC Analysis of Flavonoids}

An HPLC chromatogram of mixed flavonoid standards at $280 \mathrm{~nm}$ is shown in Figure 3, and HPLC chromatograms for one sample are provided in Figure 4. The contents of individual flavonoids in different parts of E. lathyris are listed in Table 4. It was observed that the free flavonoids of the stem included rutin and kaempferol, while the bound flavonoids of the stem included five types of flavonoids, namely, rutin, resveratrol, quercetin, baicalein, and wogonin. In the root, only kaempferol was found as the free form of flavonoid, while quercetin and kaempferol presented as bound flavonoids. Four types of flavonoids presented in free form in seed, namely, rutin, resveratrol, quercetin, and baicalein, while two types of flavonoids presented in bound form in seed, specifically quercetin and kaempferol. Two types of flavonoids presented in free form in testa, namely, rutin and quercetin.

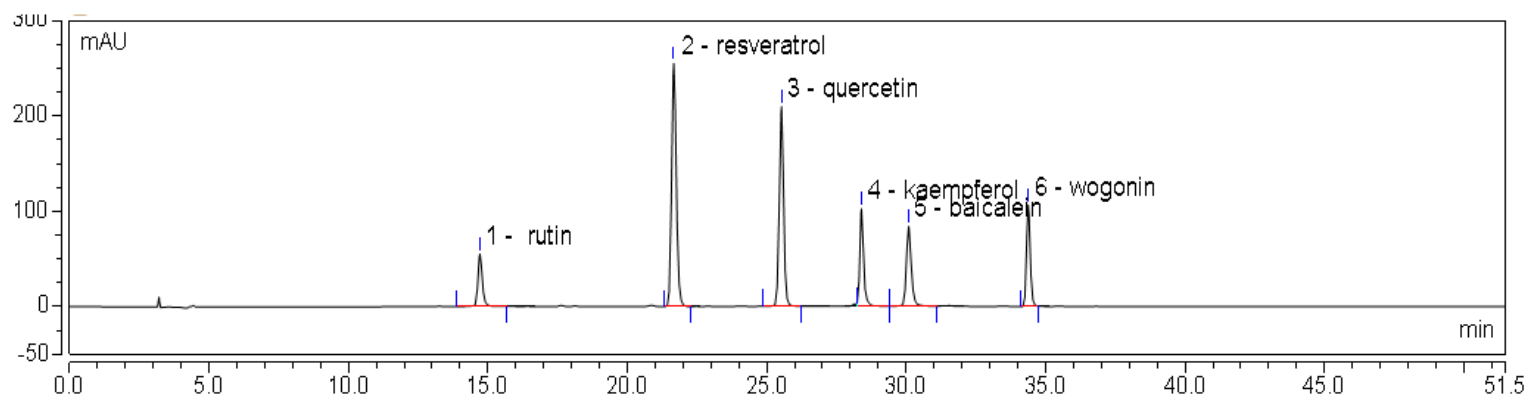

Figure 3. HPLC chromatogram of mixed flavone standards at $360 \mathrm{~nm}$. Rutin-14.743 min; resveratrol-21.642 min; quercetin-25.503 min; kaempferol-28.335 min; baicalein-30.000 min; wogonin-34.287 $\mathrm{min}$.

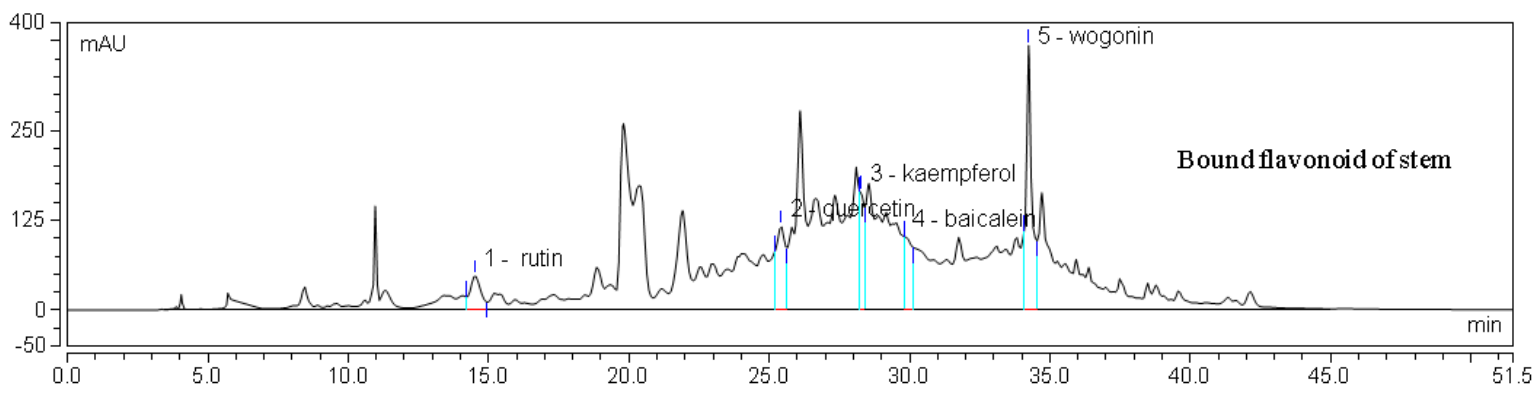

Figure 4. HPLC chromatogram of one sample flavone.

It was found that the levels of rutin, resveratrol, quercetin, baicalein, and wogonin were significantly higher in the stem than those in other parts of the plant. Kaempferol was significantly higher in root than stem. High levels of flavones and flavonol glucosides were identified by HPLC-DAD [10]. In the present study, six flavonoid components were identified in the E. lathyris by the HPLC analysis, which were rutin, resveratrol, quercetin, kaempferol, baicalein, and wogonin.

\subsection{DPPH and FRAP Assays}

The results of DPPH free radical scavenging activity and FRAP values of samples are listed in Table 5. The results showed that there were significant differences in the DPPH radical scavenging activity among the four parts $(p<0.05)$. The highest DPPH free radical scavenging activity was found in extracts of testa in E. lathyris, followed by root, seed, and stem. Furthermore, a statistically significant difference in FRAP activity was found among the four parts $(p<0.05)$, with the highest FRAP antioxidant activity found in root, and followed by seed, stem, and testa $(p<0.05)$. 
Table 4. Composition and contents of flavonoids in the Euphorbia lathyris samples (mg/g DW).

\begin{tabular}{|c|c|c|c|c|c|c|c|c|c|c|c|c|}
\hline & \multicolumn{3}{|c|}{ Stem } & \multicolumn{3}{|c|}{ Root } & \multicolumn{3}{|c|}{ Seed } & \multicolumn{3}{|c|}{ Testa } \\
\hline & Free & Bound & Total & Free & Bound & Total & Free & Bound & Total & Free & Bound & Total \\
\hline rutin & $50.65 \pm 0.11$ & $184.37 \pm 0.54$ & $235.02 \pm 0.65$ & nd & nd & nd & $78.75 \pm 0.59$ & nd & $78.75 \pm 0.59$ & $107.43 \pm 0.18$ & nd & $107.43 \pm 0.18$ \\
\hline resveratrol & & $258.17 \pm 2.04$ & $258.17 \pm 2.04$ & nd & nd & nd & $5.20 \pm 0.13$ & nd & $5.20 \pm 0.13$ & nd & nd & \\
\hline quercetin & nd & $143.15 \pm 1.24$ & $143.15 \pm 1.24$ & nd & $78.00 \pm 1.56$ & $78.00 \pm 1.56$ & $7.47 \pm 0.44$ & $16.32 \pm 0.39$ & $23.79 \pm 0.83$ & $8.73 \pm 0.06$ & nd & $8.73 \pm 0.06$ \\
\hline kaempferol & $12.87 \pm 0.59$ & nd & $12.87 \pm 0.59$ & $9.27 \pm 0.86$ & $8.97 \pm 0.21$ & $18.24 \pm 1.07$ & & $6.27 \pm 0.25$ & $6.27 \pm 0.25$ & nd & nd & nd \\
\hline baicalein & & $119.95 \pm 0.36$ & $119.95 \pm 0.36$ & nd & nd & nd & $14.47 \pm 0.48$ & nd & $14.47 \pm 0.48$ & nd & nd & nd \\
\hline wogonin & nd & $589.40 \pm 0.55$ & $589.40 \pm 0.55$ & nd & nd & nd & nd & nd & nd & nd & nd & nd \\
\hline
\end{tabular}

nd $=$ not detected. Data are expressed as means \pm SD of triplicate samples.

Table 5. DPPH and FRAP assays of Euphorbia lathyris.

\begin{tabular}{|c|c|c|c|c|c|c|c|c|c|c|c|c|}
\hline & \multicolumn{3}{|c|}{ Stem } & \multicolumn{3}{|c|}{ Root } & \multicolumn{3}{|c|}{ Seed } & \multicolumn{3}{|c|}{ Testa } \\
\hline & Free & Bound & Total & Free & Bound & Total & Free & Bound & Total & Free & Bound & Total \\
\hline $\begin{array}{l}\text { DPPH assay } \\
\text { FRAP assay }\end{array}$ & $\begin{array}{l}1.57 \pm 0.05 \mathrm{e} \\
105.71 \pm 1.51 \mathrm{~h}\end{array}$ & $\begin{array}{l}0.63 \pm 0.06 \mathrm{f} \\
71.39 \pm 2.95 \mathrm{i}\end{array}$ & $\begin{array}{l}2.20 \pm 0.11 \mathrm{~d} \\
177.10 \pm 4.46 \mathrm{f}\end{array}$ & $\begin{array}{l}2.46 \pm 0.12 \mathrm{c} \\
1807.50 \pm 17.09 \mathrm{~d}\end{array}$ & $\begin{array}{l}4.02 \pm 0.10 \mathrm{~b} \\
37.69 \pm 4.69 \mathrm{j}\end{array}$ & $\begin{array}{l}6.48 \pm 0.23 a \\
1845.19 \pm 21.78 \mathrm{c}\end{array}$ & $\begin{array}{l}0.61 \pm 0.05 \mathrm{f} \\
1131.25 \pm 6.38 \mathrm{e}\end{array}$ & $\begin{array}{l}2.04 \pm 0.10 \mathrm{~d} \\
1972.43 \pm 52.13 \mathrm{~b}\end{array}$ & $\begin{array}{l}2.65 \pm 0.15 \mathrm{c} \\
3106.68 \pm 58.51 \mathrm{a}\end{array}$ & $\begin{array}{l}61.29 \pm 0.29 a \\
69.29 \pm 4.92 \mathrm{i}\end{array}$ & $\begin{array}{l}\text { nd } \\
44.86 \pm 0.13 j\end{array}$ & $61.29 \pm 0.29 \mathrm{a}$ \\
\hline
\end{tabular}

DPPH free radical scavenging activity values are expressed as mmol Trolox $/ 100 \mathrm{~g}$ DW. FRAP activity values are expressed as $\mathrm{mg} \mathrm{FeSO}_{4} / 100 \mathrm{~g}$ DW. Values with different letters for each parameter in the same row are significantly different $(p<0.05)$. 
There was a positive correlation between the total phenolic content and the DPPH free radical scavenging activity in different parts of E. lathyris $\left(\mathrm{R}^{2}=0.69, p<0.05\right)$. The plant parts containing high total phenolic contents showed higher DPPH free radical scavenging activity. However, the total flavonoid content did not correlate with the DPPH free radical scavenging activity of E. lathyris in this study. Both the total phenolic content and total flavonoid content did not correlate with the FRAP antioxidative activity. This could be because the total expressed antioxidative activity may be associated with the relative proportions of each compound in the sample.

A study by Cai et al. reported that medicinal herbs demonstrate much stronger antioxidant activity and contain significantly more phenolics than common vegetables and fruits which are considered as good natural sources of dietary antioxidants [14]. The results of the present study indicate that the extract of E. lathyris has significant antioxidant activities, perhaps due to its high contents of phenolics and flavonoids. Many reports have suggested that the antioxidant properties in Euphorbiaceae members are mainly due to the presence of high contents of secondary metabolites, such as different types of flavonoids $[18,19]$.

In the present study, twelve standard samples were used in the HPLC analysis, and were also identified in the E. lathyris sample, which were gallic acid, chlorogenic acid, vanillic acid, $p$-coumaric acid, ferulic acid, caffeic acid, rutin, resveratrol, quercetin, kaempferol, baicalein, and wogonin. These compounds possess strong antioxidative, antibacterial, and antimutagenic properties. Our results were in accordance with the results of Ho et al. [20], who found that some phenolic acids and flavonoids possessed potent antioxidative activity, in addition to anticancer, anticarcinogenic, and antimutagenic activities. Also, ferulic acid is found in many Chinese medicinal herbs and is an effective antioxidant and vasodilatory agent. However, it is believed that thousands of phenolic compounds occur in medicinal herbs. For instance, more than 4000 kinds of flavonoids and hundreds of coumarins and lignans have been reported as naturally occurring compounds [21]. Therefore, further chemical investigation in the tested herb will be required to reveal various types of phenolic compounds.

Flavonoids and phenolics, which are known as hydrophilic antioxidants, are botanic secondary metabolites that are most abundant in plants [22]. It should be noted that there were several unknown compounds present that were not identified in this study; therefore, more research in this area is warranted.

\section{Materials and Methods}

\subsection{Plant Material}

E. lathyris was planted in Dongyang Traditional Chinese Medicine and Wild Plant Nursery of Shanxi Academy of Agricultural Sciences. Four parts of E. lathyris (namely, the stem, root, testa and seed) were collected from 10 plants in October 2012. The samples were separated, weighed, dried in the oven, pulverized and sieved (60 mesh), and finally stored at $-20^{\circ} \mathrm{C}$. The plant was identified and authenticated by Dr. Qiuxia Meng of the Institute of Agricultural Environment and Resources, Shanxi Academy of Agricultural Sciences. A voucher specimen (\#0201) was deposited at the same institute.

\subsection{Chemicals}

Gallic acid, chlorogenic acid, vanillic acid, p-coumaric acid, ferulic acid, 2,2-diphenyl-1picrylhydrazyl (DPPH) free radical, sodium borohydride, chloranil, tetrahydrofuran (THF), vanillin, 2,4,6-Tris (2-pyridyl)-s-triazine (TPTZ), and $\mathrm{FeSO}_{4}$ were purchased from Sigma Aldrich Co. (St. Louis, MO, USA). Rutin, resveratrol, quercetin, kaempferol, baicalein, and wogonin were purchased from Beijing Century Aoke Biological Technology Co. (Beijing, China). Folin Ciocalteu's reagent was purchased from Beijing Soledad Bao Technology Co. (Beijing, China). All the other chemicals were of analytical grade or HPLC grade. 


\subsection{Extraction of Samples}

Free and bound compounds of samples were extracted using the method reported by Adom et al. [23]. Briefly, a 20-g sample was mixed with $200 \mathrm{~mL} \mathrm{80 \%} \mathrm{cold} \mathrm{acetone} \mathrm{for} 10 \mathrm{~min}$ in a high-speed homogenizer. The mixture was centrifuged at $2500 \mathrm{rpm}$ for $10 \mathrm{~min}$ and the supernatant was collected. The process was repeated three times. The supernatants were pooled and evaporated to dryness at $45^{\circ} \mathrm{C}$ with a rotary evaporator to yield the extract. The free extracts were stored at $-20^{\circ} \mathrm{C}$ until analysis. The residue of the free extraction was digested for $1 \mathrm{~h}$ at room temperature in a $1000 \mathrm{~mL}$ beaker with $200 \mathrm{~mL} 2 \mathrm{M} \mathrm{NaOH}$. The mixture was then neutralized with concentrated hydrochloric acid before being extracted with $200 \mathrm{~mL}$ ethyl acetate for $10 \mathrm{~min}$. The mixture was then centrifuged at $2500 \mathrm{rpm}$ for $10 \mathrm{~min}$ and the supernatant was collected. The process was repeated three times. The supernatants were pooled and evaporated to dryness at $45{ }^{\circ} \mathrm{C}$ with a rotary evaporator. The bound extracts were stored at $-20^{\circ} \mathrm{C}$ until analysis. Prior to analysis, the extracts were resuspended in $10 \mathrm{~mL}$ deionized water, respectively.

\subsection{Determination of Total Phenolic Content (TPC)}

The Folin-Ciocalteu colorimetric method was used for total phenolic content of each sample [24]. Briefly, $100 \mu \mathrm{L}$ resuspended extract (or gallic acid standard solution) was diluted with $400 \mu \mathrm{L}$ deionized water in a glass culture tube, and $100 \mu \mathrm{L}$ Folin-Ciocalteu reagent was then added. The mixture was mixed well and incubated at room temperature for $8 \mathrm{~min}$ before adding $1 \mathrm{~mL} 7 \%$ sodium carbonate and $0.8 \mathrm{~mL}$ deionized water. The mixture was blended well and incubated for $90 \mathrm{~min}$ at room temperature. Duplicates of the sample or standard ( $200 \mu \mathrm{L}$ each in volume) were transferred to a 96-well plate. Absorbances were measured at $760 \mathrm{~nm}$ in a microplate reader. Total phenolic acid content was expressed as milligrams of gallic acid equivalents per $100 \mathrm{~g}$ of sample on a dry weight basis (mg GAE/100 g DW).

\subsection{Determination of Total Flavonoid Content (TFC)}

The total flavonoid content of each sample was determined using the sodium borohyride/chloranil-based assay [25]. Tested extracts were added to test tubes and reconstituted in $1 \mathrm{~mL}$ of THF/EtOH $(1: 1, v / v)$. Volumes of $0.5 \mathrm{~mL} 74.6 \mathrm{mM} \mathrm{AlCl}_{3}$ and $0.5 \mathrm{~mL} 50.0 \mathrm{mM} \mathrm{NaBH}_{4}$ solution were added to each test tube with $1 \mathrm{~mL}$ rutin standard solution or $1 \mathrm{~mL}$ sample solution. The tubes were shaken on the Lab-Line orbital shaker for $30 \mathrm{~min}$ at room temperature. An additional

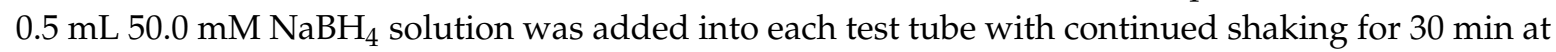
room temperature. Then, $2.0 \mathrm{~mL}$ cold $\left(4^{\circ} \mathrm{C}\right) 0.8 \mathrm{M}$ acetic acid solution was added to each test tube. The solutions were protected from the light and shaken on the orbital shaker at room temperature for 15 min after a thorough mix. Subsequently, $1 \mathrm{~mL} 20.0 \mathrm{mM}$ chloranil was added to each tube. The tubes were placed in water bath set at $95{ }^{\circ} \mathrm{C}$. The reaction solutions were cooled using tap water. The solutions were transferred to glass culture tubes and brought to a volume of $4.0 \mathrm{~mL}$ with methanol.

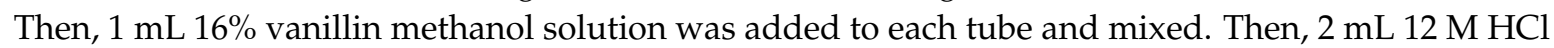
was added to each tube, mixed, and kept in the dark at room temperature for $15 \mathrm{~min}$. The solutions in the glass culture tubes were centrifuged at $2500 \mathrm{rpm}$ for $3 \mathrm{~min}$. Each solution $(200 \mu \mathrm{L})$ was added into a 96-well plate in duplicate and absorbances were measured at $490 \mathrm{~nm}$ using a microplate reader. Total flavonoid content was expressed as milligrams of rutin equivalents per $100 \mathrm{~g}$ of sample on a dry weight basis (mg RE/100 g DW).

\subsection{HPLC Analysis of Phenolic Compounds}

Phenolic compounds were separated and identified using an Ultimate3000 C18 column $(4.6 \mathrm{~mm} \times 150 \mathrm{~mm}, 5 \mu \mathrm{m})$ (Thermo Electron Corporation, Waltham, MA, USA). The mobile phase was $20 \%(v / v)$ aqueous acetonitrile $(\mathrm{pH}=3.0)$. The volume of injection for both samples and standards was $10 \mu \mathrm{L}$. The flow rate was $0.5 \mathrm{~mL} / \mathrm{min}$, and the column temperature was $30{ }^{\circ} \mathrm{C}$. Each injection 
was monitored at $280 \mathrm{~nm}$. Identification of each peak was confirmed using the retention time and absorbance spectrum of each pure compound. Percent recoveries were determined by spiking a known amount of pure compound into a sample and performing the same extraction and analytical procedures. The percent recovery for gallic acid, chlorogenic acid, vanillic acid, $p$-coumaric acid, resveratrol, and ferulic acid were higher than $90 \%(n=3)$. The linear relationship of the six phenolic acids and the results of the recovery tests are shown in Table 6.

Table 6. The linear relationship of the six phenolic acids and the results of recovery tests.

\begin{tabular}{ccccc}
\hline Phenolic Acid & Regression Equation & $\mathbf{R}^{\mathbf{2}}$ & Recovery Rate/\% & $\begin{array}{c}\text { Relative Standard } \\
\text { Deviation (RSD)/\% }\end{array}$ \\
\hline $\begin{array}{c}\text { gallic acid } \\
\text { chlorogenic acid }\end{array}$ & $Y=0.671 X-0.4473$ & 0.9995 & 97.96 & 0.67 \\
caffeic acid & $Y=0.3466 X+0.7087$ & 0.9998 & 95.95 & 0.96 \\
vanillic acid & $Y=0.4887 X+0.9467$ & 0.9996 & 99.50 & 0.30 \\
$p$-coumaric acid & $Y=1.0566 X+0.5282$ & 0.9997 & 93.87 & 0.32 \\
ferulic acid & $Y=0.6427 X-0.2327$ & 0.9999 & 97.42 & 0.15 \\
\hline
\end{tabular}

\subsection{HPLC Analysis of Flavonoids}

The determination of the flavonoid composition was conducted using an HPLC method previously reported [26], employing an Ultimate3000 C18 column $(4.6 \mathrm{~mm} \times 150 \mathrm{~mm}, 5 \mu \mathrm{m})$. The mobile phase was a mixture of solvent $\mathrm{A}(10 \%(v / v)$ aqueous acetonitrile plus $2 \mathrm{~mL} / \mathrm{L}$ acetic acid) and solvent $\mathrm{B}$ (40\% acetonitrile, $40 \%$ methanol, and $20 \%$ water plus $2 \mathrm{~mL} / \mathrm{L}$ acetic acid). The following gradient (expressed as \%B) was used: 0-17 min, 10-42.5\%; 17-23 min, 42.5-70\%; 23-26.5 min, 70\%; 26.5-31.5 $\min , 70-100 \%$; 31.5-36.5 $\mathrm{min}, 100 \%$; 36.5-52 $\mathrm{min}, 10 \%$. The flow rate was $0.5 \mathrm{~mL} / \mathrm{min}$, and the column temperature was $30^{\circ} \mathrm{C}$. The volume of injection for both samples and standards was $10 \mu \mathrm{L}$. Each injection was monitored at $360 \mathrm{~nm}$. Identification of each peak was confirmed using the retention time and absorbance spectrum of each pure compound. Percent recoveries were determined by spiking a known amount of pure compound into a sample and performing the same extraction and analytical procedures. The percent recovery for rutin, quercetin, kaempferol, baicalein, and wogonin were higher than $90 \%(n=3)$. The linear relationship of the six flavones and the results of the recovery tests are given in Table 7.

Table 7. The linear relationship of the six flavones and the results of recovery tests.

\begin{tabular}{ccccc}
\hline Flavone & Regression Equation & $\mathbf{R}^{\mathbf{2}}$ & Recovery Rate/\% & RSD/\% \\
\hline rutin & $Y=0.2751 X+0.7493$ & 0.9994 & 107.05 & 0.44 \\
resveratrol & $Y=1.3482 X+2.1331$ & 0.9993 & 91.21 & 5.15 \\
quercetin & $Y=0.4254 X-0.5830$ & 0.9998 & 97.68 & 2.05 \\
kaempferol & $Y=0.4856 X-1.0943$ & 0.9997 & 116.54 & 1.01 \\
baicalein & $Y=0.7495 X-4.5946$ & 0.9995 & 95.43 & 1.74 \\
wogonin & $Y=0.3569 X-0.4124$ & 0.9996 & 91.62 & 1.9 \\
\hline
\end{tabular}

\subsection{Ferric-Reducing Antioxidant Power (FRAP) Assay}

The FRAP assay was carried out according to the method of Benzie and Strain [27]. Briefly, $100 \mu \mathrm{L}$ of extracts and $4.9 \mathrm{~mL}$ of FRAP reagent, consisting of $100 \mathrm{mM}$ acetate buffer (pH 3.6), $10 \mathrm{mM}$ 4,6-tripryridyls-triazine (TPTZ) in $40 \mathrm{mM} \mathrm{HCl}$, and $20 \mathrm{mM}$ ferric chloride in a 10:1:1 ratio (by volume), were transferred into vials and incubated at $37^{\circ} \mathrm{C}$ for $10 \mathrm{~min}$. The FRAP reagent was prepared fresh daily and was warmed to $37^{\circ} \mathrm{C}$ in a water bath prior to use. Then, the absorbance at $593 \mathrm{~nm}$ was measured relative to a reagent blank also incubated at $37^{\circ} \mathrm{C}$. The FRAP data for samples were determined against the standard of a known FRAP value, $\mathrm{FeSO}_{4}$. All solutions were used on the day of preparation. Results were expressed as $\mathrm{mg} \mathrm{FeSO}_{4} / 100 \mathrm{~g}$ DW. 


\subsection{DPPH Free Radical Scavenging Activity}

DPPH free radical scavenging activity was measured using a modification of the method by Brand-Williams et al. [28]. Briefly, $2 \mathrm{~mL}$ of different concentrations of sample extracts were allowed to react with $4 \mathrm{~mL}$ DPPH solution for $30 \mathrm{~min}$ in the dark after mixing. The absorbance at $517 \mathrm{~nm}$ was measured relative to a reagent blank also incubated under the same conditions. The percentage inhibition was calculated against a control and compared to a Trolox standard curve $(60-200 \mu \mathrm{g} / \mathrm{mL})$. The DPPH radical scavenging rate (\%) was calculated as follows:

$$
\text { Radical scavenging rate }(\%)=\left(1-\frac{A_{x} \times A_{t}}{A_{0}}\right) \times 100
$$

where $A x$ is the absorbance of test compounds, $A_{t}$ is the absorbance of test compounds with $4 \mathrm{~mL}$ anhydrous ethanol as the blank reaction, and $A_{0}$ is the absorbance of ethanol solution $(95 \%, v / v)$ as the blank reaction.

The absorbance at $517 \mathrm{~nm}$ was measured relative to a reagent blank. The percentage inhibition was calculated against a control and compared to a Trolox standard curve $(60-200 \mu \mathrm{g} / \mathrm{mL})$.

\subsection{Statistical Analysis}

All extractions and analyses were performed in triplicate. All values were expressed as means \pm standard deviation (SD). One-way analysis of variance (ANOVA) followed by Tukey test was computed to determine significant differences between the means by SPSS Statistics 19. A significant difference was defined at $p<0.05$ or 0.01 . Correlation coefficients were determined by the Excel program.

\section{Conclusions}

The results showed that $E$. lathyris is rich in active components, such as phenolics and flavonoids. The highest total phenolic content was recorded in the testa of E. lathyris, while the highest total flavonoid content was obtained in the root. Meanwhile, the testa extract of E. lathyris showed higher DPPH free radical scavenging activity than root, stem, and seed extracts, but the seed extract showed higher FRAP antioxidant activity. Total phenolic contents in different parts of E. lathyris and their DPPH free radical scavenging activity were positively correlated. As the phytochemical contents in different parts of E. lathyris varied significantly, we could select appropriate parts to obtain a high yield of target phytochemicals.

To our knowledge, this is the first time that the flavonoids and other phenolics of E. lathyris have been analyzed with HPLC, although diterpenoids of E. lathyris seed have been measured in the literature without including the phenolic and flavonoid contents in different parts of E. lathyris. The analysis of the type and content of polyphenols in different parts of E. lathyris can shed a light on the further development and utilization of this Chinese medicinal plant.

Acknowledgments: This Research Project Supported by Shanxi Scholarship Council of China (2015-018); Shanxi International Cooperation (2014081059).

Author Contributions: L.Z.Z., and Q.T. designed the experiments. Q.T., C.W., and Y.N. performed the experiments. L.Z.Z., Q.T., and Y.N. analyzed the data. W.Y., and Q.X.M. contributed reagents, materials, and analytical tools. L.Z.Z., Q.T., and Q.X.M. composed the paper.

Conflicts of Interest: The authors declare no conflict of interest.

\section{References}

1. Nemethy, E.K.; Otvos, J.W.; Calvin, M. Analysis of extractables from one Euphorbia. J. Am. Oil Chem. Soc. 1979, 56, 957-960. [CrossRef]

2. Escrig, P.V.; Iglesias, D.J.; Corma, A.; Primo, J.; Primo-Millo, E.; Cabedo, N. Euphorbia characias as bioenergy crop: A study of variations in energy value components according to phenology and water status. J. Agric. Food Chem. 2013, 61, 10096-10109. [CrossRef] [PubMed] 
3. Liao, S.G.; Zhan, Z.J.; Yang, S.P.; Yue, J.M. Lathyranoic acid A: First secolathyrane diterpenoid in nature from Euphorbia lathyris. Org. Lett. 2005, 7, 1379-1382. [CrossRef] [PubMed]

4. Itokawa, H.; Ichihara, Y.; Watanabe, K.; Takeya, K. An antitumor principle from Euphorbia lathyris. Planta Med. 1989, 55, 271-272.

5. Hou, X.R.; Wan, L.L.; Zhan, Z.J.; Li, C.P.; Shan, W.G. Analysis and determination of diterpenoids in unprocessed and processed Euphorbia lathyris seeds by HPLC-ESI-MS. J. Pharmaceut. Biomed. Anal. 2011, 1, 197-202. [CrossRef]

6. Lu, J.; Li, G.; Huang, J.; Zhang, C.; Zhang, L.; Zhang, K.; Li, P.; Lin, R.; Wang, J. Lathyrane-type diterpenoids from the seeds of Euphorbia lathyris. Phytochemistry 2014, 104, 79-88. [CrossRef] [PubMed]

7. Hohmann, J.; Evanics, F.; Vasas, A.; Dombi, G.; Jerkovich, G.; Máthe, I. A novel lathyrane diterpenoid from the roots of Euphorbia lathyris. J. Nat. Prod. 1999, 62, 176-178. [CrossRef] [PubMed]

8. Zhang, F.L.; Luo, Y.H.; Wei, X.Y.; Wang, N. Non-terpenoid constituents from the seeds of Euphorbia lathyri. J. Tropical Subtropical Botany 2009, 17, 298-301.

9. Jiao, W.; Lu, L.; Deng, M.C.; Shao, H.W.; Lu, R.H. Study on chemical constituents in seeds of Euphorbia lathyris. Chin. Traditional Herb. Drugs 2010, 41, 181-187.

10. Surveswaran, S.; Cai, Y.Z.; Corke, H.; Sun, M. Systematic evaluation of natural phenolic antioxidants from 133 Indian medicinal plants. Food Chem. 2007, 102, 938-953. [CrossRef]

11. Adom, K.K.; Liu, R.H. Antioxidant activity of grains. J. Agric. Food Chem. 2002, 50, 6182-6187. [CrossRef] [PubMed]

12. Szakiel, A.; Paczkowski, C.; Pensec, F.; Bertsch, C. Fruit cuticular waxes as a source of biologically active triterpenoids. Phytochem. Rev. 2012, 11, 263-284. [CrossRef] [PubMed]

13. Liu, H.; Qiu, N.; Ding, H.; Yao, R. Polyphenols contents and antioxidant capacity of 68 Chinese herbals suitable for medical or food uses. Food Res. Int. 2008, 41, 363-370. [CrossRef]

14. Cai, Y.; Luo, Q.; Sun, M.; Corke, H. Antioxidant activity and phenolic compounds of 112 traditional Chinese medicinal plants associated with anticancer. Life Sci. 2004, 74, 2157-2184. [CrossRef] [PubMed]

15. Dragland, S.; Senoo, H.; Wake, K.; Holte, K.; Blomhoff, R. Several culinary and medicinal herbs are important sources of dietary antioxidants. J. Nutr. 2003, 133, 1286-1290. [PubMed]

16. Xiao, Z.P.; Peng, Z.Y.; Peng, M.J.; Yan, W.B.; Ouyang, Y.Z.; Zhu, H.L. Flavonoids health benefits and their molecular mechanism. Mini-Rev. Med. Chem. 2011, 11, 169-177. [CrossRef] [PubMed]

17. Ni, Q.X.; Xu, G.Z.; Wang, Z.Q.; Gao, Q.X.; Wang, S.; Zhang, Y.Z. Seasonal variations of the antioxidant composition in ground bamboo sasa argenteastriatus leaves. Int. J. Mol. Sci. 2012, 13, 2249-2262. [CrossRef] [PubMed]

18. Subhan, N.; Alam, M.A.; Ahmed, F.; Awal, M.A.; Nahar, L.; Sarkar, S.D. In vitro antioxidant property of the extract of Excocaria agallocha (Euphorbiaceae). DARU-J. Faculty. Pharm. 2008, 16, 149-154.

19. Kadri, A.; Gharsallah, N.; Damak, M.; Gdoura, R. Chemical composition and in vitro antioxidant properties of essential oil of Ricinus communis L. J. Med. Plant Res. 2011, 5, 1466-1470.

20. Ho, C.T.; Osawa, T.; Huang, M.; Rosen, R. Food Phytochemicals for Cancer Prevention II: Teas, Spices, and Herbs; American Chemical Society: Washington, DC, USA, 1994; pp. 144-153.

21. Iwashina, T. The structure and distribution of the flavonoids in plants. J. Plant Res. 2000, 113, $287-299$. [CrossRef]

22. Srivastava, A.; Greenspan, P.; Hartle, D.K.; Hargrove, J.L.; Amarowicz, R.; Pegg, R.B. Antioxidant and anti-inflammatory activities of polyphenolics from Southeastern US range blackberry cultivars. J. Agric. Food Chem. 2010, 58, 6102-6109. [CrossRef] [PubMed]

23. Adom, K.K.; Sorrells, M.E.; Liu, R.H. Phytochemicals and antioxidant activity of milled fractions of different wheat varieties. J. Agric. Food Chem. 2005, 53, 2297-2306. [CrossRef] [PubMed]

24. Singleton, V.L.; Orthofer, R.; Lamuela-Raventos, R.M. Analysis of total phenols and other oxidation substrates and antioxidants by means of Folin-Ciocalteu reagent. Methods Enzymol. 1999, 299, 152-178.

25. He, X.J.; Liu, D.; Liu, R.H. Sodium borohydride/chloranil-based assay for quantifying total flavonoids. J. Agric. Food Chem. 2008, 56, 9337-9344. [CrossRef] [PubMed]

26. Fuentes-Alventosa, J.M. Identification of flavonoid diglycosides in several genotypes of Asparagus from the Huetor-Tajar population variety. J. Agric. Food Chem. 2007, 55, 10028-10035. [CrossRef] [PubMed]

27. Benzie, I.F.F.; Strain, J.J. The ferric reducing ability of plasma (FRAP) as a measure of "antioxidant power": The FRAP assay. Anal. Biochem. 1996, 239, 70-76. [CrossRef] [PubMed] 
28. Brand-Williams, W.; Cuvelier, M.E.; Berset, C. Use of a free-radical method to evaluate antioxidant activity. LWT-Food Sci. Technol. 1995, 28, 25-30. [CrossRef]

Sample Availability: Free and bound extraction compounds of Euphorbia lathyris L. are available from the authors. (CC BY) license (http:/ / creativecommons.org/licenses/by/4.0/). 